\title{
Construction of appropriate model for Enrolment Projection of India
}

\author{
Vishal D. Pajankar ${ }^{1}$ \\ ${ }^{1}$ National Council of Educational Research and Training, New Delhi INDIA \\ vdp1234@rediffmail.com ${ }^{1}$
}

Article History: Received: 10 November 2020; Revised: 12 January 2021; Accepted: 27 January 2021;

Published online: 05 April 2021

Abstract: There are different models used for enrolment projection in the education system. Of them ARIMA, double exponential, logistic curve method, reconstructive cohort, and regression model, method are commonly used. Every model has its suitability under certain conditions and with prior assumptions. In India, no attempt was made to estimate enrolment except in 1996. The logistic curve method was adopted to estimate enrolment between 1996 - 2001. In the present situation, an attempt has been made to estimate school enrolment for the next years. The present paper discusses fitting the best model for estimating enrolment for the next few years.

Keywords: Enrolment projection, reconstructive cohort method, primary stage, upper primary stage, secondary stage.

\section{Introduction}

Every country has a unique school education system. India also has its school education system. It has fourlayer systems. From grade 1 to grade 5 is called as a primary stage, grade 6 to grade 9 is called as an upper primary stage, grade 9 and 10 is called as a secondary stage and grade 11 and 12 is called as a higher (or senior) secondary stage. All states and Union Territories of the country have adopted the same pattern of school education system. The country has a defined entry age in the school system that is 6 years of age. Once a child completes 6 years of age then s/he will be eligible to get enrolled in the school system at grade 1. Accordingly, the stage-wise age group is also defined by the Government of India, children in the age group of 6 to 10+ years, are supposed to be in the primary stage, children in the age group of 11 to 13+ years, are supposed to be in the upper primary stage, children in the age group of 14 to $15+$ years, are supposed to be in secondary stage and children in the age group of 16 to $17+$ years, are in higher (or senior) secondary stage. However, there are some exceptions in entry age of a child in the system.

Once the child gets enrolled in the school system, the flow of s/he movement is depends on her/his academic performance. Though, after the implementation of the Right To Education Act 2009, the country has adopted the No Detention Policy in the country at the Elementary stage that is in primary and upper primary stages (from grade 1 to 8$)$. But $100 \%$ transition of the children from grade $i$ to grade $i+1(1 \leq i \leq 7)$ is not happened. Always, there will be a number of dropouts or repeaters remain in the system. The education flow model of children transitions from grade $i$ to grade $i+1 \quad(1 \leq i \leq 9)$, repetition, and moving out from the systems is very well explained in [1] and [2]. The model in figure1 demonstrates the implications for enrolment at future dates with explicit assumptions about the continuation of past and current trends. The flow model can also be used to reconstruct the flows of a chart of education systems. The flow model is used to explain the behavioral relationship which determines in part the parameters playing such an important role in the model. Such as repetition rates, dropout, promotions, new entrants in the system at any class. Sometimes dropout occurs due to the influence of social factors forced to leave the systems against their wishes or individuals' perceptions of their short-term and long-term employment and earning prospects.

In some cases, dropouts for a school may be transferred to another school, district, or administrative area without informing the parent-school or without issuing school leaving certificate document or any other legal document. In such a situation, he/she may be treated as a new entrant for the new school. From the above-given base model of the flow of students in the system, let us elaborate in detail the fundamental concepts involved in the Transaction Model. 


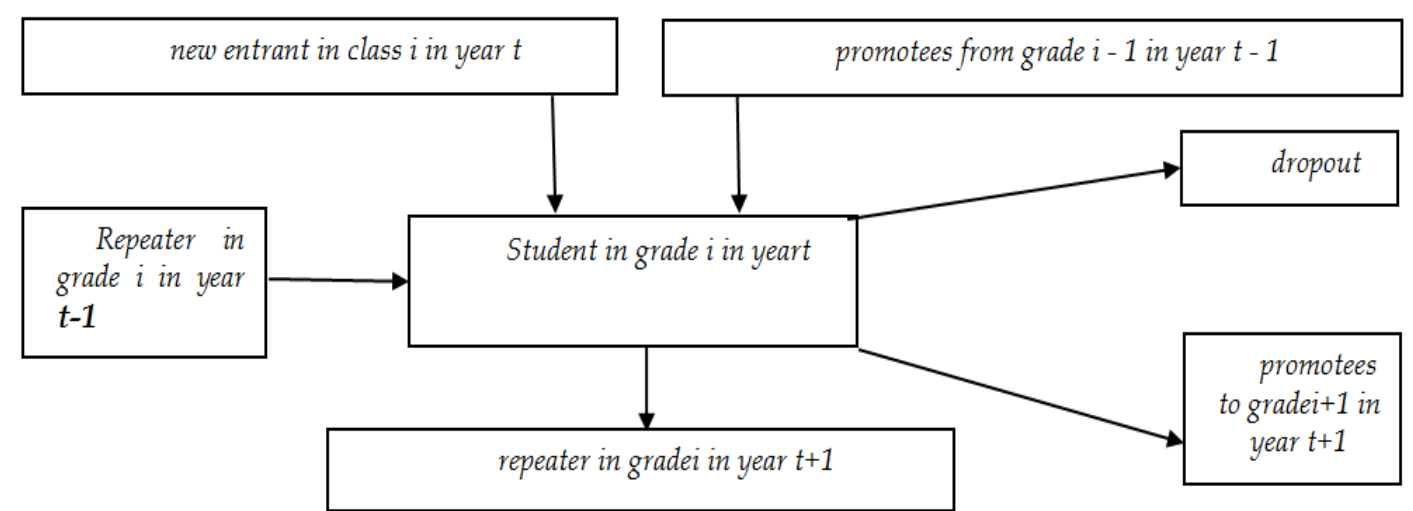

Figure 1. Base Model of student's flow in the school system [1]

\section{Literature Review}

While fitting the appropriate model of enrolment projection, several researchers have used different models according to their suitability and availability of resources. A structural model for projecting public school enrolment by grade, progrmme, and district used in [3]. The advantage of specifying a structural model is that many of the standard approaches to forecasting enrolment emerge as special cases of its reduced form equations explained in [3]. The National Center for Educational Statistics (NCES) 2025 used double exponential smoothing and multiple linear regression method for projection of education statistics to 2025 [4]. NCERT used the logistic curve method to project the enrolment of $1997-2001$. They used prior data collected under the third, fourth, fifth, and sixth All India School Education Survey ${ }^{1}$ conducted during 1973, 1978, 1986, and 1993 respectively. The achievement of the study was that the error between actual data and projected data was inbetween $2 \%$ to $5 \%$ only, which is statistically acceptable [5]. Cohort method for projection is explained by [6] and [7]. [7] studied the cohort-survival ratio method in the projection of school attendance and [7] explained reconstructive cohort methods with other aspects such as basic concepts, educational planning, methods of analyzing and projecting school enrolment, flow methods, RCM, projection of teachers' supply and demand, etc.

Several methods of enrolment projections have been explored. Four methods are identified as an appropriate method in the Indian context namely; auto regression integrated moving average method (ARIMA), double exponential method, logistic curve method, and reconstructive cohort method.

\section{Construction of Projection Model}

The projection of enrolment for the coming years is useful for planning and policy decisions for a country. Allocation of infrastructure, the demand of human resources including academics and secretarial staff, provisions for socially disadvantaged groups, etc. are being estimated on the basis for projected figures. Enrolment has three important components that play a vital role in the enrolment projection; namely, promotion rate, repetition rate, and dropout rate. Since enrolment is the function of the population so the population of children also useful in enrolment projection. Change in population proportion directly reflects in the enrolment.

In India, a child who complete 6 years of age, is eligible to get enrolled at grade 1 in a school. It means that in total population, the population of 6-year children is supposed to enroll at grade 1 in a school, so the equation of grade enrolment can be defined as

$$
E_{i}^{t}=P_{A g_{-} 6}^{t}
$$

\footnotetext{
${ }^{1}$ All India School Education Survey is a census survey of all schools in India. It covers all schools including government schools, local body schools, private aided schools and private unaided schools from grade1 to 12 situated in any part of the country. It includes urban are schools, rural schools, tribal area school, forest schools, oriental schools, etc. It collects all information from the schools such as type of school, enrolment, teachers, available infrastructure, incentive schemes, accessibility of schooling facility in rural areas, etc. First survey conducted in year 1957. Till then nine surveys has conducted in the country.
} 
where, $P_{A g_{-} 6}^{t}$ is the population of $A g=6$ in time $t$ and $E_{i}^{t}$ is the enrolment in grade $i=1$ in time $t$. But it is not true in a real-life situation. Because a good number of children of under aged children $(i<6)$ and over-aged children $(i>6)$ are also get enrolled with children of aged $(i=6)$ in grade 1 . So the equation (1) is redefined as

$$
E_{C l_{-} I}^{t}=x_{1} P_{A g_{-} 5}^{t}+x_{2} P_{A g_{-} 6}^{t}+x_{3} P_{A g_{-} 7}^{t}+x_{4} P_{A g_{-} 8}^{t}+x_{5} P_{A g_{-} 9}^{t}+x_{6} P_{A g_{-} 10+}^{t}
$$

where, $P_{A g_{-} 5}^{t}, P_{A g_{-} 6}^{t}, P_{A g_{-} 7}^{t}, P_{A g_{-} 8}^{t}, P_{A g_{-} 9}^{t}, P_{A g_{-} 10+}^{t}:$ child population in aged $i=5,6,7,8,9,10+$ years respectively and $x_{i}$ : coefficient of the child population of aged $i(i=5,6,7,8,9,10+)$ years in grade 1 in time $t$ and

$$
\sum_{i=5}^{10+} x_{i}=1=I R_{C l_{-} I}^{t}
$$

where, $I R_{C l_{-} I}^{t}=E_{C l_{-} I}^{t} *\left(P_{A g_{-} 6}^{t}\right)^{-1}$, the intake rate of the child. If all new entrants in grade 1, start schooling at the same age then the proportion of this age-group population in time $t$ with the enrolled students in grade 1 in that time can be taken into consideration to estimate the proportion of the population.

While fitting the appropriate model of enrolment projection, several researchers have used different models according to their suitability and availability of resources. As discussed in the literature review, the several methods of enrolment projections have been explored, out of them four methods are identified as an appropriate method in the Indian context namely; auto regression integrated moving average method (ARIMA), double exponential method, logistic curve method, and reconstructive cohort method. A tryout exercise has been conducted with an available enrolment for the year 2012-2015 and to estimate enrolment for the years 2017 and 2018. The finding of the suggestive models is as

- ARIMA method smoothened the data sharply and gave an almost straight uniform line however in actual situation it is not possible

- Double exponential methods produced an increasing linear trend while in decreasing child population rate, linearly increasing enrolment was incorrect.

- The basic assumption for fitting logistic curve was that data should be in an increasing order however there is much noise in the data of enrolment available through UDISE. Even growth in enrolment of two consecutive years was not showing any trend. So the logistic curve was not fitting in the available data. In the study, it was assumed that there is no dropout in the system, hence the dropout rate

Due to these results, it was decided to adopt the reconstructive cohort method for the projection of enrolment and construct the model according to the requirement of the study. Hence, for Reconstructive Cohort Method, some basic requirements are (i) child population at aged 6 years (according to the grade 1 entry policy of India); (ii) apparent Intake Rate for time $t$; (iii) grade enrolment data for time $t$; (iv) repetition rate at grade $i(i=1,2, \ldots$ , 9) for time $t$; and (v) promotion rate of class $i(i=1,2, \ldots, 9)$ for time $t$.

The components of the enrolment can be calculated as; the apparent intake rate: $I R_{i}^{t}=E_{i}^{t} *\left(P_{A g_{-} i}^{t}\right)^{-1}(i=1)$; repetition rate, $R R_{i}^{t}=R_{i}^{t+1} *\left(E_{i}^{t}\right)^{-1}$; and promotion rate, $P R_{i}^{t}=\left(E_{C l_{-}(i+1)}^{t+1}-R_{C l_{i+1}}^{t+1}\right) *\left(E_{C l_{i}}^{t}\right)^{-1}$ where $(2 \leq i \leq$ 10).

Hence the model is constructed in two levels. At the first level, the model is constructed for grade $i(i=1)$

$$
E_{i}^{t}=\left(P_{A g=6}^{t} * A R_{i}^{t}\right)+\left(E_{i-1}^{t-1} * R R_{i-1}^{t}\right)
$$

In the second level, the model is constructed for grade $\mathrm{i}$ where $(2 \leq i \leq 10)$ is as

$$
E_{i}^{t}=\left(E_{i-1}^{t-1} * P R_{i-1}^{t}\right)+\left(E_{i}^{t-1} * R R_{i}^{t}\right)-\left(E_{i-1}^{t-1} * D_{i-1}^{t}\right)
$$

In the above model, it is assumed that there is no dropout in the system. So, the dropout will be assumed to zero, that is, the dropout rate, $D_{i-1}^{t}=Z E R O$. That's implies

$$
E_{i}^{t}=\left(E_{i-1}^{t-1} * P R_{i-1}^{t}\right)+\left(E_{i}^{t-1} * R R_{i}^{t}\right)
$$

The model is given in (4) and (5) are similar. The only difference is that when there are dropouts in the system, model (4) will be applied and when no dropout in the system then model (5) will be used. 


\section{Result}

The reconstructive cohort method is one of the best methods in the estimation of enrolment for the next $n$ years. Using the model, the enrolment is calculated upto 2025, given in table 1. From the table, it is found that enrolment at primary stage starts decreasing from year 2011 and enrolment at upper primary starts declining after 2016-17. Since, the population is the function of the enrolment. According to the report of RGI Census 2011, the growth rate of child population of India is declining. Change in growth of population is directly implies on the enrolment. As a result, enrolment at primary stage and upper primary is recoded declining.

Table 1. Growth in School Enrolment (2001-02 To 2025-26)

(Figures in Lakhs)

\begin{tabular}{|c|c|c|c|c|c|c|}
\hline \multirow{2}{*}{ Year } & \multicolumn{3}{|c|}{ Primary (I-V) } & \multicolumn{3}{|c|}{ Upper Primary } \\
\hline & Boys & Girls & All & Boys & Girls & All \\
\hline 2001-02 & 636 & 503 & 1139 & 261 & 187 & 448 \\
\hline $2002-03$ & 651 & 573 & 1224 & 263 & 206 & 469 \\
\hline 2003-04 & 684 & 599 & 1283 & 273 & 215 & 487 \\
\hline 2004-05 & 697 & 611 & 1308 & 285 & 227 & 512 \\
\hline $2005-06 *$ & 705 & 616 & 1321 & 289 & 233 & 522 \\
\hline 2006-07* & 684 & 634 & 1319 & 254 & 221 & 475 \\
\hline 2007-08* & 695 & 647 & 1341 & 270 & 239 & 509 \\
\hline 2008-09* & 694 & 650 & 1344 & 280 & 254 & 534 \\
\hline 2009-10* & 686 & 644 & 1330 & 281 & 259 & 540 \\
\hline 2010-11* & 697 & 654 & 1352 & 299 & 280 & 578 \\
\hline 2011-12* & 708 & 663 & 1371 & 318 & 301 & 620 \\
\hline 2012-13* & 696 & 652 & 1348 & 333 & 317 & 649 \\
\hline 2013-14* & 686 & 638 & 1324 & 341 & 323 & 665 \\
\hline 2014-15* & 676 & 629 & 1305 & 345 & 327 & 672 \\
\hline 2015-16* & 669 & 622 & 1291 & 347 & 329 & 676 \\
\hline 2016-17* & 642 & 596 & 1238 & 340 & 321 & 661 \\
\hline $2017 * *$ & 634 & 587 & 1222 & 342 & 320 & 661 \\
\hline $2018 * *$ & 630 & 582 & 1212 & 338 & 314 & 652 \\
\hline 2019** & 627 & 578 & 1205 & 333 & 310 & 643 \\
\hline $2020 * *$ & 623 & 571 & 1194 & 330 & 306 & 636 \\
\hline $2021 * *$ & 623 & 570 & 1193 & 325 & 302 & 628 \\
\hline $2022 * *$ & 623 & 568 & 1191 & 322 & 298 & 620 \\
\hline $2023 * *$ & 621 & 565 & 1186 & 319 & 294 & 613 \\
\hline $2024 * *$ & 617 & 562 & 1179 & 319 & 294 & 613 \\
\hline $2025 * *$ & 614 & 560 & 1174 & 319 & 293 & 612 \\
\hline
\end{tabular}

\section{Conclusion}

The reconstructive cohort is one of the best models for the projection of enrolment. The model is chosen out of different available model. It is constructed by considering all possible parameters of the system involved in the transition of a child. The model is then tested with India's enrolment projection by 2025.

According to the [10] and [11], the population of India is increasing from 12,10,855 (2011) to $14,25,908$ (2026) (figures in ' 000 as reported in [11]) however the child population in age group 0-14 years is declining from 3,73,89 (2011) to 3,39,222 (2026) (figures in ' 000 as reported in [11]). At the same time, the share of children in age group 0-14 years in the population is 30.9\% (2011) and which is goes to 23.8\% (2026). As a result the count of school going children are decreasing in proportion. From the result of the study presented in the table 1, the enrolment of children is also reported declining at primary stage as well as upper primary stage. As discussed in section [1], the age group of children at primary stage is 6-10+ years and the age group of children at upper primary stage is 11-13+ years, respective declining is reflecting in the outcome of the report.

\section{Limitation}

- There is much noise in source data so it was difficult to find the trend in the enrolment;

- Promotion rate and repetition rate for three years assumed to be constant and hence estimated accordingly. 


\section{Acknowledgment}

The author is very much thankful to the editor, reviewers of the paper for the valuable comments and suggestions in the improvement of the paper. Their comments and suggestions help in the improvement the quality of the paper.

\section{References}

1. Vishal D. Pajankar and Sridhar Srivastava, "Trend and Projection of School Enrolment by 2025", New Delhi: NCERT, (2018). (unpublished)

2. Vishal D. Pajankar and Sridhar Srivastava, "An approach of estimating School Enrolment with Reconstructive Cohort Approach” Journal of Physics: Conference Series, 1366 (2019) 012116, pp. $1-9$.

3. William B. Stronger and Schultz Ronald, "Models for Projecting School Enrolment", Journal of Educational Evaluation and Policy Analysis, vol. 3. no..5. (1981), pp. 75-81.

4. National Center for Educational Statistics, "Projection of Education Statistics to 2025", Institute of Education Sciences, U.S. Department of Education, (2017).

5. NCERT, "Year wise Projected Enrolment in 1995-2001 at different school stages", Department of Educational Surveys and Data Processing, New Delhi, (1996).

6. William J. Webster, "An Empirical Comparison of selected Enrolment Projection Formulas", The Journal of Educational Research, vol. 64. no. 8, (1971), pp. 375-381.

7. UNESCO, "Statistical Analysis of Demographic and Education Data in Zambia", Lusaka: Division of Statistics on Education Office of Statistics, (1884).

8. M. D. Orwig, et. al, "Enrolment Projection Models for Institutional Planning. Journal of Higher Education", vol. 1, no.4, (1972), pp. 435-448.

9. Ilhan Ozturk, "The role of education in economic development: A theoretical perspective", Journal of Rural Development and Administration, vol XXXIII, no. 1, (2001), pp. 39-49.

10. UNDP and P. M. Kulkarni, "Population Projection of India", UNDP Report, (2017), (unpublished).

11. NCP-MHFW, "Population Projections for India and States 2011-2036", Report of Technical Group on Population Projections, Ministry of Health and Family Welfare, Govt. of India, (2020).

\section{Authors}

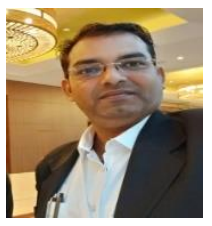

Dr. Vishal D. Pajankar, Assistant Professor (Statistics) at Educational Survey Division, NCERT, New Delhi has experience of about 17 years of active service. At NCERT, he is involved in large scale surveys such as All India School Education Survey (AISES) and National Achievement Surveys (NAS). In 8th All India School Education survey, he was coordinator of Western region states and also part of national level team. He also coordinated NAS Class V (Cycle 4), core team member of NAS 2017 at Class 3, 5, \& 8, and NAS Class $X$ (Cycle 1 and 2). He is also involved in test designing, item development, assessment framework, planning, data quality management, and other related activities. He has visited few countries and credited around 40 research articles and completed 9 research projects. 